\title{
The Use of a Viability Index as a Better Measure of Departmental and Program Strength
}

Andrew L. Luna, Sherry Kendrick, and Melissa Johnson

\section{About the Authors}

Andrew L. Luna is the executive director of Decision Support and Institutional Research. Sherry Kendrick and Melissa Johnson are research analysts in Decision Support and Institutional Research. The authors are with Austin Peay State University.

\section{Abstract}

Although many institutions and government agencies count degrees as the sole measure of determining departmental or program viability, this method fails to consider other factors such as how many students who are within programs are present to replace students who graduated from those programs or how many credit hours were generated in the area. This article highlights an easy-to-create, ratio-driven metric that can help an academic department or program to determine its overall strength.

Keywords: program viability, ratios, program prioritization, academic affairs, finance

The AIR Professional File, Spring 2021

Article 152 https://doi.org/10.34315/apf1522021

Copyright (c) 2021, Association for Institutional Research 


\section{INTRODUCTION}

As budgets become leaner and requirements for state and federal accountability grow stronger, higher education administrators are seeking to make smarter and more-effective business decisions to maximize revenue, cut costs, and reduce increases in tuition costs amidst a skeptical and financially strapped public. To achieve these goals, administrators must rely on performance indicators that are useful, effective, and easy to understand, and that can be used strategically to move the institution forward in uncertain times. Rather than relying on tried-and-true performance measures that carry little relevance, colleges and universities must explore the use of better means to measure institutional health. Therefore, higher education administrators, lawmakers, and the public should rely less on measures such as the Integrated Postsecondary Education Data System (IPEDS) graduation rates as part of the performance indicator toolkit; those rates were never intended to be a measure of institutional quality.

The purpose of this article is to briefly discuss the misconception behind traditional performance indicators as adequate measures of institutional or program strength, and to introduce ratios that are more logical and more useful in evaluating institutional health, academic strength, and program viability. Ratio analysis is one of the most powerful tools in higher education. Ratios are used as devices to analyze and interpret the health of an institution and to assist in determining the direction in which it should move. Ratio analysis can also help administrators evaluate whether the institution is doing better in a given year than it was the year before. In addition, ratio analysis can indicate if the institution is doing better or worse than other institutions within the same geographic location or with a similar role, scope, and mission.

\section{THE FALLACY BEHIND THE IPEDS 6-YEAR GRADUATION RATE}

To say that the IPEDS graduation rate is heavily used by higher education as well as by those governmental and media institutions that monitor the rate's progress is an understatement. The graduation rate is used within institutional promotional materials, performance indicators for state funding, college rankings, peer reviews, and federal government oversight. This little-understood statistic is freely repeated by administrators, legislators, and news reporters with little regard as to how the number is defined and why it was initially used. Briefly, the IPEDS 6-year graduation rate begins with all first-time, full-time, degree-seeking undergraduate students. This group is placed into a cohort and tracked over a period of time to determine which of these students graduated, which are still attending, and which have left the institution. Therefore, the 6 -year rate is the total number of students within the cohort who graduated within a 6 -year period divided by the total number of the cohort within the first-year class. This statistic, however, was never intended for use as an overall measure of institutional health or effectiveness. Rather, it was used to help track the success of student athletes.

In 1985 the National Collegiate Athletic Association (NCAA) began to require its member schools to report graduation rate data so that the organization could compare student athletes to the non-athlete student body (Brown, 2014). Given that most NCAA student athletes are not transfer students, are required to attend school full time, and must be degree seeking, it was natural to create a comparative database with these attributes. 
Seeing that these comparative data were useful, US Senators Bill Bradley and Edward Kennedy introduced the Student Right-to-Know and Campus Security Act in early 1989. While the institutional comparisons were required within NCAA, the federal bill, which was passed into law in 1990, tied Title IV funds to its new mandate (Brown, 2014). Congress was concerned that the significant revenue from college games was so great that the educational mission of the university is too easily forgotten, and their fears were supported. In 1989 a US General Accounting Office (GAO) report found that, within the NCAA's largest schools, the graduation rates of men's football and basketball athletes were significantly lower than the graduation rates for all other students (GAO 1989). It is clear that, although the law was intended to protect the educational interests of students, many administrators and lawmakers found the new comparative data to be extremely useful for other analyses as well.

According to Cook and Pullaro (2010), looking at the first-time, full-time cohort gives only partial information because this group accounts for only about $60 \%$ of the total aggregate entering class within institutions. That means that $40 \%$ of the entering class is not included in the IPEDS Graduation Rate Survey (GRS) report. Looking at trend data by highest degree offered from 2010 to 2018 through the IPEDS data retrieval system, one can observe that, among the masters- and baccalaureate-granting institutions, roughly 45\% are not in the GRS cohort; and among the doctoralgranting institutions roughly $40 \%$ are not in the cohort (Figure 1).

Figure 1. IPEDS GRS Cohort as Percentage of Total Entering Class by Highest Degree Offered

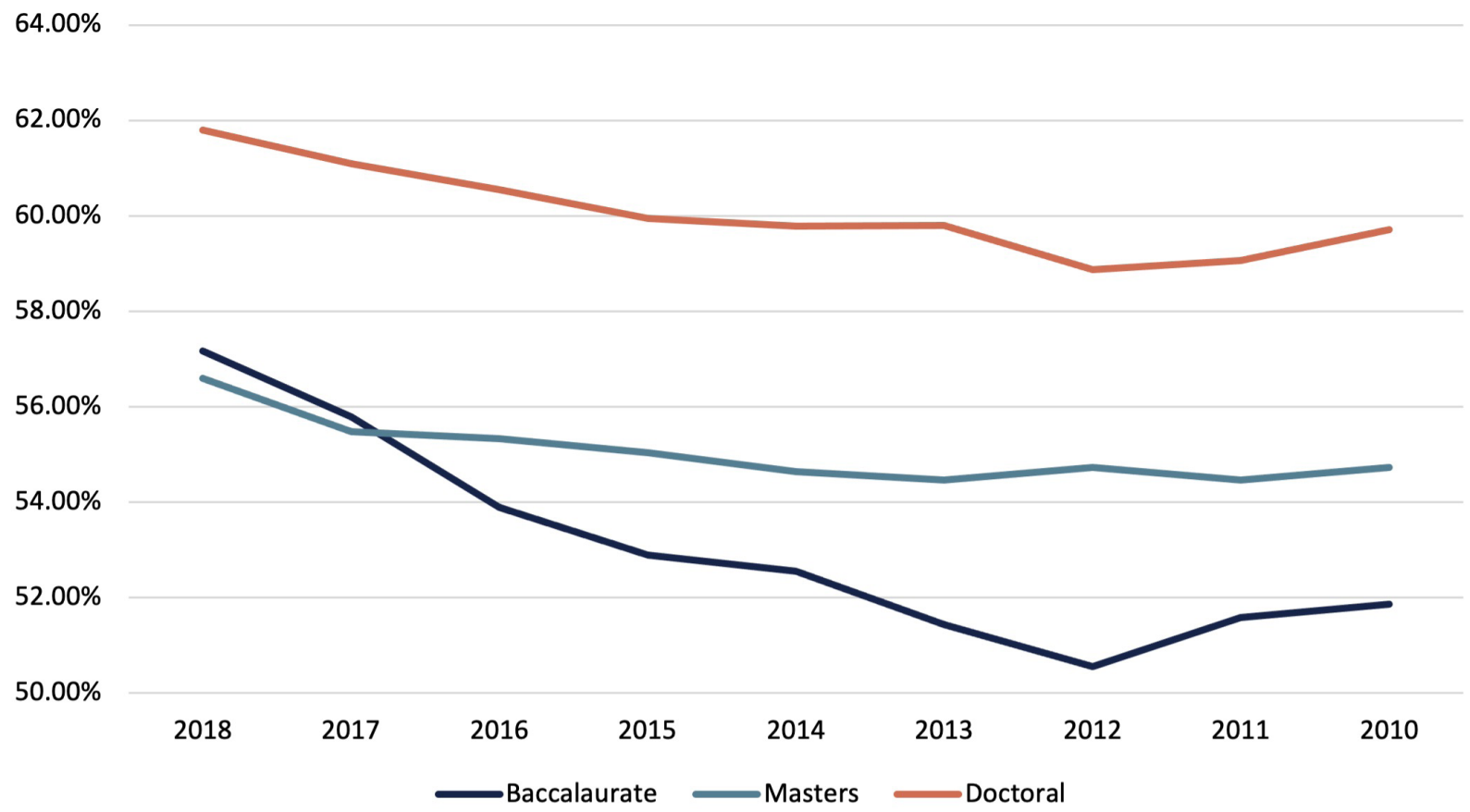


With such a large number of students not being counted in the official graduation statistics due to students that either attend part time or have transferred from another institution, many have argued that the traditional GRS statistics is ineffective in determining institutional viability and strength. In fact, the National Center for Education Statistics announced in 2017 that new captured data would allow institutions to report graduation rates of part-time and transfer students (Lederman, 2017). While many, especially within the 2-year schools, applaud the decision, others believe that the move may be too little and too late.

In an effort to generate more accurate performance measures, greater attention has been given to alternative methods than to traditional graduations rates and measures of institutional viability. One such alternative method is to use a ratio of degrees to the number of students enrolled. This ratio can be observed from the institutional level down to the degree level. According to Cook and Pullaro (2010), the degree-to-enrollment ratio (DER), unlike graduation rates, provides valuable information on both enrollment trends and completions trends. Accordingly, DER is gaining popularity and has been used by the American Council on Education as well as by the Delta Cost Project, which is a combined database project between the National Center for Education Statistics and the American Institutes for Research to provide analyses and resources to aid in the understanding of what colleges do with their money

\section{OTHER PERFORMANCE MEASURES USED}

In addition to the 6-year graduation rate, other performance indicators have been used by state agencies with varying degrees of success. According to a report from the National Conference of State Legislatures (2015), 32 states have some type of performance-based funding model for their higher education institutions, with many of the outcome measures at the institutional level. Some models do include outcome measures at the department or program level.

For instance, one measure used in many models is a count of the number of degrees granted over time. Usually there is a threshold to meet: the average number of degrees during a specific period cannot fall below a certain number. Credit hour completion is another widely used measure whereby institutions track the percentage of students who complete 30, 60 , and 90 credit hours. Additional performance measures include enrollment counts by major, course completion rates, and number of students who transfer in to the institution.

Simple whole or mixed data are used in most of these measures with percentage of achievement present in some. Most of these measures address only one component of viability. For instance, a state may be interested in a count of graduates by program over a period of 3 years where the average number of degrees should not fall below 10 for undergraduate students. While this measure is important, it does not take into consideration the number of credit hours that each department or program may generate to support other programs and/or the core curriculum.

One measure that is used by a few states is the number of degrees earned per 100 full-time equivalent (FTE) students. This measure clearly takes into consideration both the number of degrees and the number of FTE students within that department or program. Because degrees are being compared 
with credit hour production through the FTE calculation, the resulting quotient can be nebulous and difficult to understand. Moreover, since different institutions and state agencies often calculate FTE differently, the resulting measures may get lost in translation. Though this particular measure is limiting, the concept of using ratios becomes compelling.

\section{THE USE OF RATIOS IN HIGHER EDUCATION}

While the use of ratio analysis is mainly found in finance, it should not be confined to that area. Various types of managers and administrators should be interested in ratios so that they can better understand the institution as a whole and the division and/or department in which they reside, or to understand how various components within an institution relate to each other (Tahey et al., 2010). Therefore, ratios have wide applications and are of vital importance in the overall management of higher education. For instance, ratio analysis may be used for the following:

- Decision-making: Ratio analysis helps in making decisions from the information provided in financial, enrollment, and resource situations. It can be used by an individual academic department to determine if a new program should be established, or it can be used institutionally as part of its strategic initiatives regarding enrollment management, pricing, outreach, and so on.

- Forecasting and planning: Ratios calculated for a number of years can serve as a guide for the future. Meaningful conclusions can be drawn as to the overall positioning of an institution in relation to where it wants to go.
- Communication: The strengths and weaknesses of a department or program can be communicated to both internal and external constituents in an easier and moreunderstandable manner by the use of ratios. The information obtained through ratio analysis can also be conveyed in a meaningful manner to the individuals for whom it is meant, allowing for quicker response or action.

- Coordination: Oftentimes, higher education tends to work in silos where one department or division seems to work independently of another department or division. The use of ratio analysis can help tie these silos together by easily conveying the connections of the various components within higher education.

- Control: Ratio analysis helps to create effective controls throughout the institution. Standard ratios can be used to take a corrective action at the right time or to prevent a situation from ever happening. Furthermore, by controlling various elements within the institution, it may more effectively reach its strategic objectives (Minter et al., 1982).

The basis for the effective application of ratio analysis is a clear understanding of the institutional mission as well as those strategic steps to take the institution into the future. Every institution should have a mission that is tied to both financial and nonfinancial measurement to help it gauge its progress. These measures help guide the institution in determining what resources are available and how it will use those valuable resources.

This is all part of the strategic management model discussed by Brown (1986). This model (Figure 2) allows an institution to develop how it will move forward based on an established mission as well as on measurable indicators. 
Figure 2. Strategic Management Model

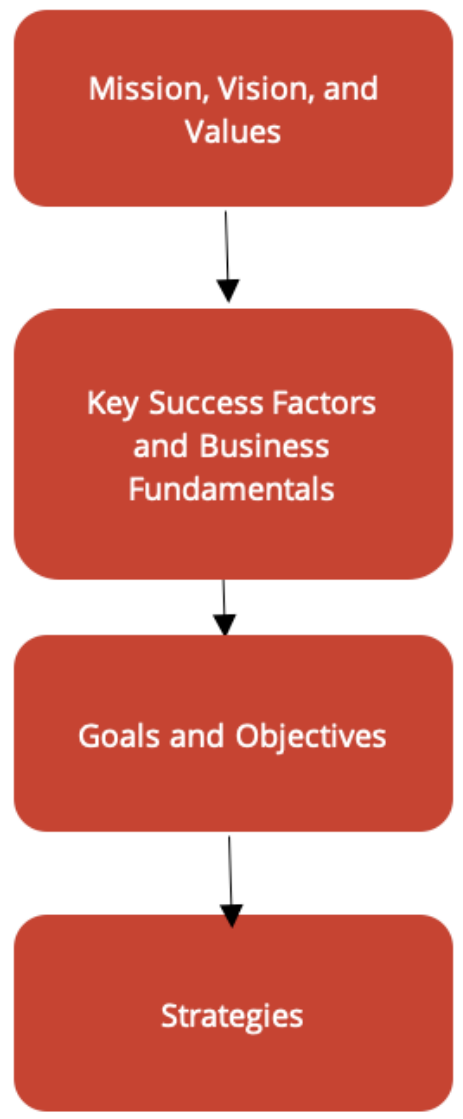

Source: Brown 1986

In order to realize its desired outcomes, the institution defines its mission, vision, and values; determines its key success factors and business fundamentals; establishes goals and objectives; and forms strategies. Clearly, ratios can serve as a major component of this process.

So, why is it important to use ratios over simple whole or mixed data? The use of only whole or mixed data may be fallacious and could have a negative impact on the institution. For instance, an institution may believe itself to be in good shape when it sees increases in new first-year enrollment from year to year. This trend could be misleading, however, if the yield rate of high school students from the traditional feeder schools is actually decreasing. In other words, although new first-year numbers might be increasing, the institution might actually see a decrease in the total number of high school graduates who could enroll. For example, say an institution enrolls 500 students from a high school graduating class of 1,000 . The yield rate in this example would be 50\%. The following year, the institution enrolls 550 students from a graduating class of 1,500. While there is an increase in the number of students enrolled from 500 to 550, the yield rate of students who could enroll dropped from $50 \%$ to $37 \%$. This yield gives a better picture of enrollment than the primary data alone.

Simple whole or mixed data in themselves are a report of an event that has no economic meaning. These numbers stand alone, and are unrelated to anything else that they affect or that affects them. To make events meaningful, those numbers must be compared with data that relate to them (Tucker, 1961). For example, if a vehicle is driven 300 miles in a day, this statistic has no relationship to the vehicle's fuel economy. If it is driven 300 miles on 20 gallons of gasoline, however, the economy evaluated can be said to be 15 miles driven for every gallon of gas consumed. This is considered an elementary ratio (Tucker, 1961). Distance traveled is not the only factor in the economy of the vehicle, however. Other factors include the speed at which the vehicle traveled, the terrain on which it traveled, and the size of the vehicle itself, among others. When these factors are combined, the results create an advanced or tertiary ratio that gives a better picture of the vehicle's economy.

Simple data have absolute values, ratios have only relative values in that they have no real meaning unless they are observed longitudinally. Only when they are so observed can the true value of the ratio 
be appreciated. Preparing ratios can be a daunting task, however. Higher education institutions have so much simple data that it can be difficult to decide which data to use and how to relate them with other data.

The researcher begins by asking the question, "What does the institution want the ratio analysis to tell it?" Later, the researcher must ask, "What can the institution do with the information?"

\section{A CLOSER LOOK AT THE VIABILITY INDEX}

While simple or elementary ratios provide a higher quality of managerial information than primary data, they do have their limitations. Specifically, elementary ratios capture only a portion of an event or action and, therefore, may be artificially isolated from other factors that have an impact on the overall decision process. Once two primary pieces of data are used to create various elementary ratios and those ratios are tracked over a period, important information can be obtained from their relationship. This information is limited, though, because the inferences or assumption constructed on elementary ratios are based solely on the data elements used to create them and have no bearing on the external relationships that exist with other important data.

Within an academic department, the number of majors (i.e., students in programs) and graduates within those programs is very important in order for researchers to address overall health and viability. In general, the more majors there are to replace the students who graduate and leave the program, the better or more viable that department is. The primary data of majors and graduates can be useful, especially when combined into an elementary ratio where the relationships between majors and graduates can be compared with trend analysis. Again, according to Cook and Pullaro (2010), the DER, unlike graduation rates alone, provides valuable information on both enrollment trends and completion trends. While these data are important when addressing the strength of the major, other factors (e.g., credit hour production), which give a more-complete story about the department, are not contained within the ratio.

Credit hour production is another important element to measure departmental viability: the amount of credit hours produced by a department is a direct measure as to how much tuition revenue that department generates for the institution. Furthermore, credit hour production transcends the count of student majors and graduates within a department because it demonstrates to what extent a department provides academic support for other programs outside the department as well as the department's contribution to the institution's undergraduate core curriculum. Therefore, any analysis of departmental viability should contain information on the counts of majors and graduates as well as credit hour production.

In order to get broader, more-effective ratios to address program viability, higher-order ratios are required. These more-advanced ratios combine elementary ratios and/or other simple data in a way that gives more-precise information that is broader in scope within the department (Tucker, 1961). As used in this article, the Viability Index is a higherorder ratio that combines two elementary ratios: 
Viability Index = (Majors $_{j} /$ Degrees Awarded $)_{j}$ *

((Department CHRS / Institutional CHRS $) * 100)$

Whereas,

$j=$ academic year
CHRS = credit hours
Majors = Number of students who declared majors
within an academic department during period $j$

Degrees $=$ Number of degrees awarded within an academic department during period $j$

Department CHRS = Total credit hours generated by an academic department during period $j$

Institutional CHRS = Total credit hours generated by institution during period $j[/]$

For purposes of this article, only undergraduate data are used from a public university in the US Southeast. While the Viability Index is equally useful for graduate degrees, students, and credit hours, it is not used in this article in order to focus on the process of gathering and analyzing the ratios rather than the difference between the undergraduate and graduate indexes. If graduate programs are used in the model, credit hours would need to be weighted based on course level and/or discipline. Accordingly, the ratio of majors to degrees awarded will be referred to as the replacement ratio, whereas the ratio of department credit hours to institutional credit hours will be referred to as the production ratio. When combined into a higher-order ratio, the seminal elements of departmental production and replacement can be assessed together with minimal effort. Since the outcome measure of the Viability Index is a score between 0 and 100, those departments with higher scores are, in effect, more viable than departments with lower scores.
Furthermore, by observing trend data, it is relatively easy to track whether a department's viability is improving, staying the same, or declining.

\section{MAJORS TO DEGREE RATIO (REPLACEMENT)}

This elementary ratio determines the institution's strength to replace graduating students with other students. These other students consist of both new majors and existing majors. Therefore, a 6:1 ratio indicates that, for every student within a department who graduates, there are six students earning credit hours who are replacing that graduating student. It is understood that, throughout the United States, not every student attending a college or university will graduate from that institution. In some cases, the student will transfer to another institution, and, in other cases, the student will stop out or drop out of higher education altogether. It is important, therefore, that an academic department or program ensure there are enough students enrolled in a given year to replace those students who graduated that same year.

Historically, undergraduate ratios of between 6:1 and 10:1 are considered strong for an academic program, while ratios between 4:1 and 6:1 are considered strong for graduate programs. Numbers significantly lower than these may signal a degeneration of the department or program because, if the trend does not change, there will not be enough majors to support those students who graduate, leading to negative growth and possibly the demise of the program. To the contrary, significantly higher ratios do not necessarily signify stronger programs. A significantly higher number of majors than graduates could indicate areas where there is high attrition. In other words, while many students are entering the program, most will change 
to other programs within the institution or transfer to other institutions.

An example of the replacement ratio is found in Figure 3. Here, three departments are shown with total enrollment, total degrees awarded, and the replacement ratio. The ratio for Department $A$ is a little over 7:1, signifying that there is an adequate number of majors to replace those students who graduated. Department B, however, indicates that there is just over a 1:1 ratio of majors to graduates, indicating that, even though the enrollment of majors is high, the department has barely enough majors to support the graduates it is losing. To the contrary, Department C demonstrates a very high replacement ratio, indicating possible high attrition for the department. This higher ratio could also be present when departments or programs are new and, therefore, have not yet built up the graduate base. The higher ratios could also follow a significant internal program redesign, or could be influenced by external market factors. Again, when analyzing these ratios it is important to observe them longitudinally and in context to what is happening within the department.

\section{Figure 3. Replacement Ratio Example}

\begin{tabular}{|l|r|r|r|}
\hline \multicolumn{4}{|c|}{ Replacement Ratio Example } \\
\hline Measure & \multicolumn{1}{|l|}{$\begin{array}{l}\text { Dept. } \\
\text { A }\end{array}$} & $\begin{array}{l}\text { Dept. } \\
\text { B }\end{array}$ & \multicolumn{1}{l|}{\begin{tabular}{l} 
Dept. \\
\hline Majors
\end{tabular}} \\
\hline Degrees Awarded & 31 & 325 & 427 \\
\hline Replacement Ratio & 7.58 & 265 & 11 \\
\hline
\end{tabular}

While this ratio is more effectively used within an individual academic department or program, it is also useful to an institution by college or in the aggregate.

\section{DEPARTMENTAL CREDIT HOURS TO INSTITUTIONAL CREDIT HOURS RATIO (PRODUCTION)}

This elementary ratio is the percentage of total institutional credit hours generated by a particular department in relation to the total number of institutional credit hours generated. The higher the percentage, the more the academic department is contributing to institutional credit hour production. The production of credit hours within a department usually takes on at least one of three different forms. First, the department will generate credit hours to directly support the programs within the department. For example, the biology department generates credit hours in biology courses for students within the biology program. Second, departmental credit hours are generated because of support and/or fulfilment of courses within another department. An example would be nursing majors who need biology courses as part of their program requirements. A third form would be departmental credit hours that are generated as part of an overall institutional requirement. For example, students fulfilling their core curriculum requirements have the option of taking biology courses as part of their science core requirements.

Depending on the academic department, the amount of credit hours generated within each of the three forms is dependent on the role of the department. For example, the English department will generally produce many credit hours even though it may have a small to moderate number of majors. This production is mainly attributed to the general education core required courses offered within the English department. In contrast, however, the nursing program's credit hour production is focused primarily on nursing majors. 
An example of the production ratio is found in Figure 4. Here, the departmental credit hour production is compared to credit hour production for the institution. As can be seen, Department A indicates a larger percentage share of credit hours as compared to both Departments B and C. This larger share could typically mean that the department might not only be generating credit hours for the major, but might also be supporting the core curriculum as well as other programs. Department B indicates an average share of credit hour production while Department $\mathrm{C}$ demonstrates a department with a much smaller credit hour share. Observing the ratio longitudinally will clearly indicate the position of a department or program regarding its credit hour production.

\section{Figure 4. Production Ratio Example}

\begin{tabular}{|l|r|r|r|}
\hline \multicolumn{4}{|c|}{ Production Ratio Example } \\
\hline Measure & Dept. A & Dept. B & Dept. C \\
\hline Institutional CHRS & 265,100 & 265,100 & 265,100 \\
\hline Department CHRS & 25,400 & 11,050 & 3,250 \\
\hline Production Ratio & 9.58 & 4.17 & 1.23 \\
\hline
\end{tabular}

Note: CHRS $=$ credit hours.

Similar to the replacement ratio, the production ratio is used most effectively within an individual academic department or program, but it is also useful to an institution by college or in the aggregate.

\section{THE RELATIONSHIP BETWEEN REPLACEMENT RATIO AND PRODUCTION RATIO}

While most performance indicators within higher education revolve around one or two primary measures, the Viability Index is based on two ratios and four primary sources. Observed independently, both the replacement and the production ratios can impart information that primary data alone cannot. For instance, the replacement ratio indicates how strong a department or program is by how many majors are available to replace those who graduate. Clearly, because overall enrollments are dwindling nationwide, it becomes increasingly important for a department as well as an institution to determine both high-demand and low-demand programs.

Observed over time, the replacement ratio discernibly tracks demand growth and whether a department can recruit and maintain enough majors to support it. While the replacement ratio is an important component to overall departmental or program health, its information is limited. For instance, some departments may not have had as many majors as others but they produce many credit hours in the form of general education. In order to reinforce the role, scope, and mission of the institution, administrators should also look at how the department or program supports the institution in terms of overall credit hour production. In this instance, the production ratio's market share measure ensures that all departments or programs are being assessed by how many credit hours they produce as a percentage of total institutional credit hours.

The Viability Index, therefore, becomes a fine balance between how many majors a department or program can recruit and maintain as well as how many credit hours it produces for the department and the institution. The Viability Index is seen in Figure 5 where two theoretical departments are shown with the primary data of majors, degrees, and credit hour production, along with the subsequent replacement and production ratios. Within Department $X$, the replacement ratio is 
lower than within Department $Y$, indicating fewer majors in Department $X$ to replace students who graduate or leave than in Department $Y$. Department $X$ is producing a significantly higher number of credit hours as a percent of total credit hours than Department Y produces, however. In each case the department could make the argument that it is equally supporting the institution, but in different ways. Because the Viability Index takes both the replacement and production ratios into consideration, the overall index value will determine which of the two is stronger.

\section{Figure 5. Relationship between the}

\section{Replacement and Production Ratios}

\begin{tabular}{|c|c|c|}
\hline \multicolumn{3}{|c|}{$\begin{array}{l}\text { Relationship between the Replacement and } \\
\text { Production Ratios }\end{array}$} \\
\hline Measure & Dept. $X$ & Dept. Y \\
\hline Majors & 185 & 265 \\
\hline Degrees Awarded & 65 & 61 \\
\hline $\begin{array}{l}\text { Replacement } \\
\text { Ratio }\end{array}$ & 2.85 & 4.34 \\
\hline Institutional CHRS & 265,100 & 265,100 \\
\hline Department CHRS & 12,751 & 7,105 \\
\hline Production Ratio & 4.81 & 2.68 \\
\hline
\end{tabular}

Note: $\mathrm{CHRS}=$ credit hours .

Once the replacement and production ratios have been computed, the Viability Index is calculated by simply taking the product of the two ratios. As shown in Figure 6, Department Y has a higher replacement ratio while Department $X$ has a higher production ratio. When the product of the two are calculated, the difference in the Viability Index between the two departments is negligible. Therefore, departments with higher replacement ratio but lower production ratio, or vice versa, in this case can use the Viability Index equally to demonstrate overall health.
Figure 6. Viability Index

\begin{tabular}{|c|r|r|r|}
\hline \multicolumn{4}{|c|}{ Viability Index } \\
\hline Unit & Replacement & Production & Viability \\
\hline Dept. X & 2.85 & 4.81 & 13.69 \\
\hline Dept. Y & 4.34 & 2.68 & 11.63 \\
\hline
\end{tabular}

\section{APPLICATION OF THE VIABILITY INDEX}

Now that the Viability Index has been defined and demonstrated, the three panels in Figure 7 will indicate how the index is used with an actual institution. Here, the Viability Index was computed for all academic departments within a public masters-comprehensive university in the Southeast. The three panels of Figure 7 demonstrate the Viability Index over a 3-year period. The individual bars indicate the departments while the horizontal lines denote the average annual Viability Index for all departments. The Y-axis indicates the Viability Index. At first glance, all three panels clearly show those departments that are performing close to or above the mean, while other departments indicate performance well above or below the mean.

Departments 5, 14, 15, and 18 show strong viability while Departments 2, 3, 16, and 24 indicate significantly weaker viability. Department 1 has decreased viability during the 3-year period while Department 17 has steadily increased viability. According to all three panels, Department 26 is very low in viability. This lower index score is, in part, attributed to lower market demand for this particular major. Conversely, Department 27 indicates an increase from the first year to the second and a significant increase from Year 2 to Year 3. This increase is due, in part, to a redesign of the program during the second year and was mainly driven by the increased number of majors. 
Figure 7a. Viability Index by Department, 2018-2019

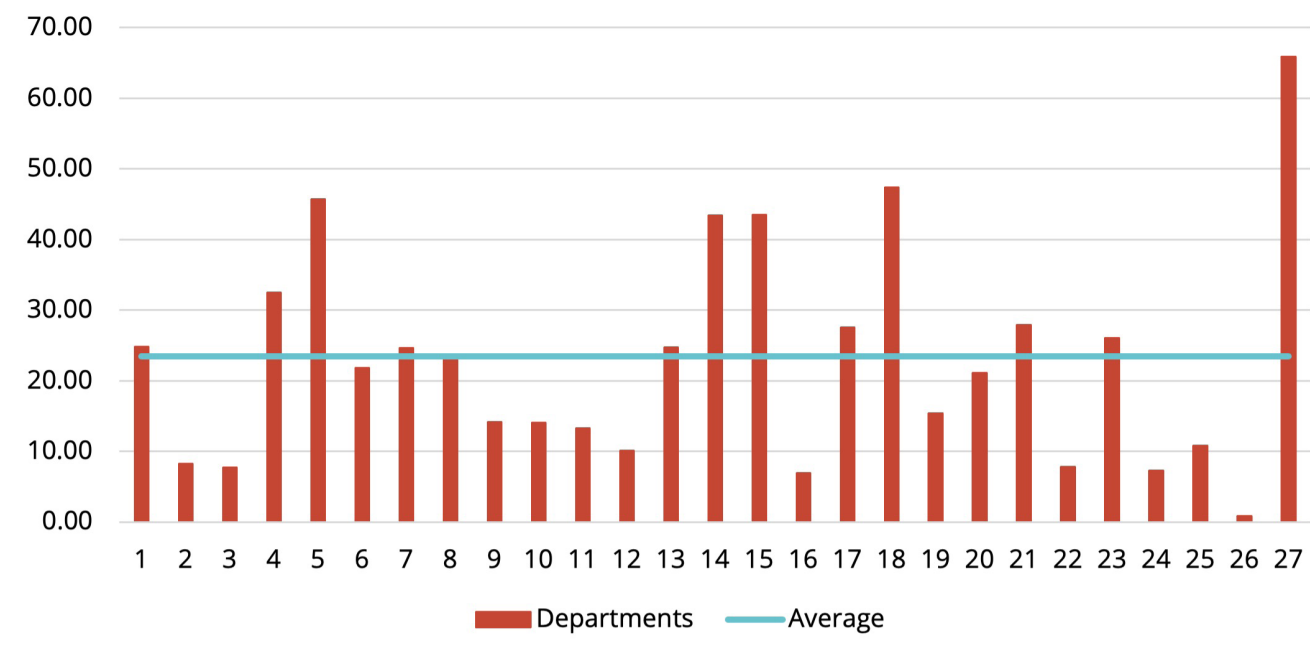

Figure 7b. Viability Index by Department, 2017-2018

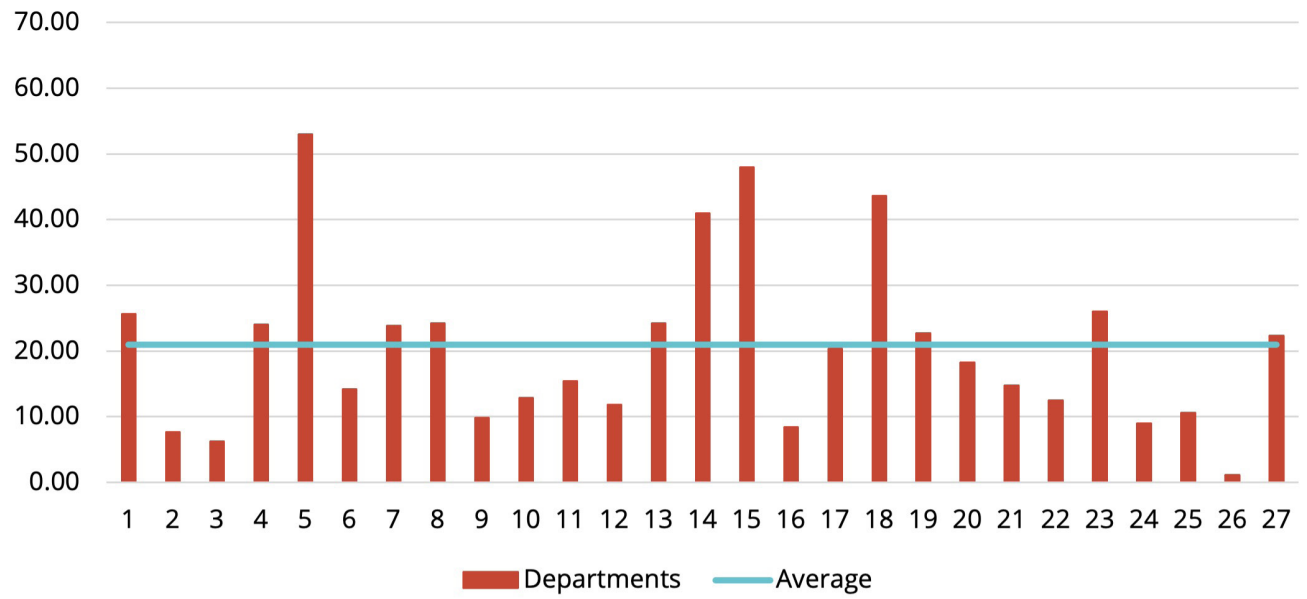

Figure 7c. Viability Index by Department, 2016-2017

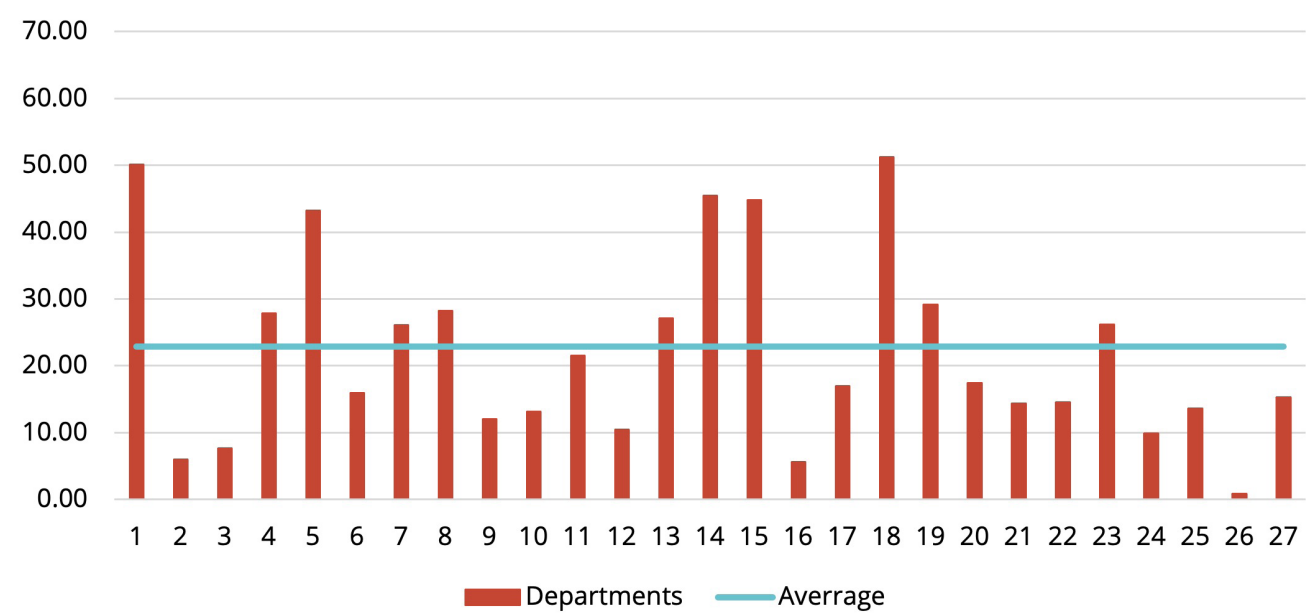


THE MATRIX: ANOTHER WAY OF DETERMINING OVERALL VIABILITY

When used together, the replacement ratio and the production ratio give a multidimensional view of a department's/program's viability. While the replacement ratio is a good measure of recruiting and retention strength, the production ratio indicates how much revenue is generated in relation to the institution as a whole. Combining the two ratios into a single measure or Viability Index reveals how the balance of the two ratios serves as a practical measure of overall departmental/program health. This balance between the replacement ratio and the production ratio can be also demonstrated in a matrix form. As shown in Figure 8, the $2 \times 2$ matrix reveals four possible quadrants or states into which each department or program may fall.

The $\mathrm{Y}$-axis represents the replacement ratio while the $\mathrm{X}$-axis represents the production ratio. The vertical line indicates the mean value of the production ratio for all the departments/programs while the horizontal line indicates the mean value of the replacement ratio for all the departments/ programs.

\section{Figure 8. The Viability Matrix}

Figure 8: The Viability Matrix

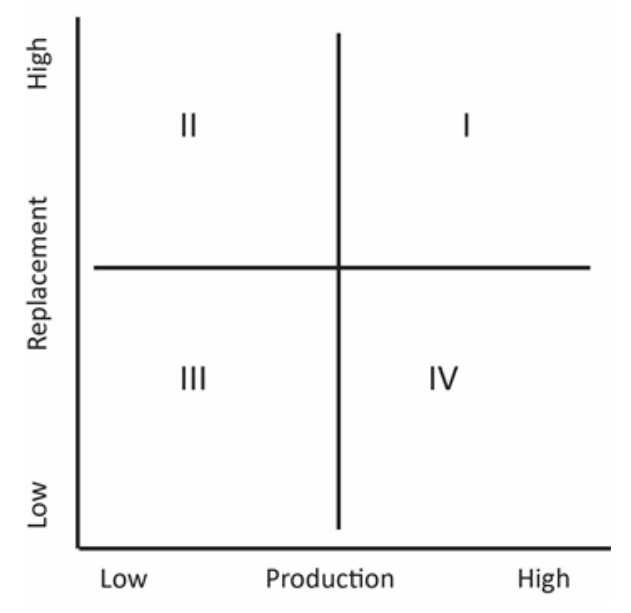

Quadrant I indicates those departments or programs that have a higher replacement ratio and a higher production ratio. Unless the replacement ratio is very high (indicating possible attrition), departments or programs within this state would be considered strong. Quadrant II depicts a higher replacement ratio with a lower production ratio. Departments or programs falling within this state, while healthy, experience lower credit hour production and, generally, may not be either highdemand programs or programs that offer significant general education credit hours.

Quadrant III indicates a state where the department or program experiences a lower replacement ratio and a lower production ratio. Contrary to Quadrant I, those departments or programs falling into this state are considered weaker. Quadrant IV indicates a lower replacement ratio and a higher production ratio. Departments or programs falling within this state, while healthy, experience fewer students to replace those who are graduating. If significant, this decrease in students could be attributable to changing market conditions for the major.

As with ratios, the matrix is best observed longitudinally where year-to-year changes can be detected. From this vantage point, it is easy to see if a department/program stays in the same quadrant, shows gradual movement from its current quadrant to another, or experiences a significant shift from one quadrant to another.

Furthermore, when reading the matrix, it is important to notice the department's or program's position within the quadrant. For example, departments or programs that fall close to where the horizontal and vertical lines connect (equilibrium), or those that are close to another quadrant are in a marginal state and, through time, could move from one quadrant to another. Those 
departments or programs that are deep within a quadrant, however, are assumed to be in a stable position.

\section{APPLICATION OF THE VIABILITY MATRIX}

Examining the same departments within a public southeastern masters-comprehensive university as was used earlier, Figure 9a indicates that the replacement ratio mean is almost 7:1 while the production ratio mean is almost 4:1 for Year 1 . Departments 1 and 11 have significantly higher replacement ratios than most of the other departments, skewing the mean and causing the other departments to cluster close to the horizontal and vertical lines. Department 18 is slightly within stronger Quadrant I along with 8, 19, and 4. The majority of the departments, however, fall within Quadrant III, indicating possible weakness. Many of these departments are close to either Quadrant II or Quadrant IV, however, indicating that further observation during subsequent years is needed to determine if the observed values are stable or shifting.

Plotting the matrix for Year 2, Figure 9b clearly reveals change and indicates that Department 1's higher replacement ratio the year before did affect other departments as well. In this panel, Department 1 's higher replacement ratio was not a factor and, subsequently, many of the departments in Quadrant III during Year 1 moved to Quadrant II. This indicates that Department 1's replacement ratio did tend to skew the other departments. Department 10 moved horizontally from Quadrant IV to Quadrant III, however, and Department 17 moved diagonally from Quadrant IV to Quadrant II, indicating that departmental change was not caused solely by the skewness of Department 1's replacement ratio during Year 1.

\section{Figure 9a. Production Ratio in Relation to Replacement Ratio by Department, Year 1}

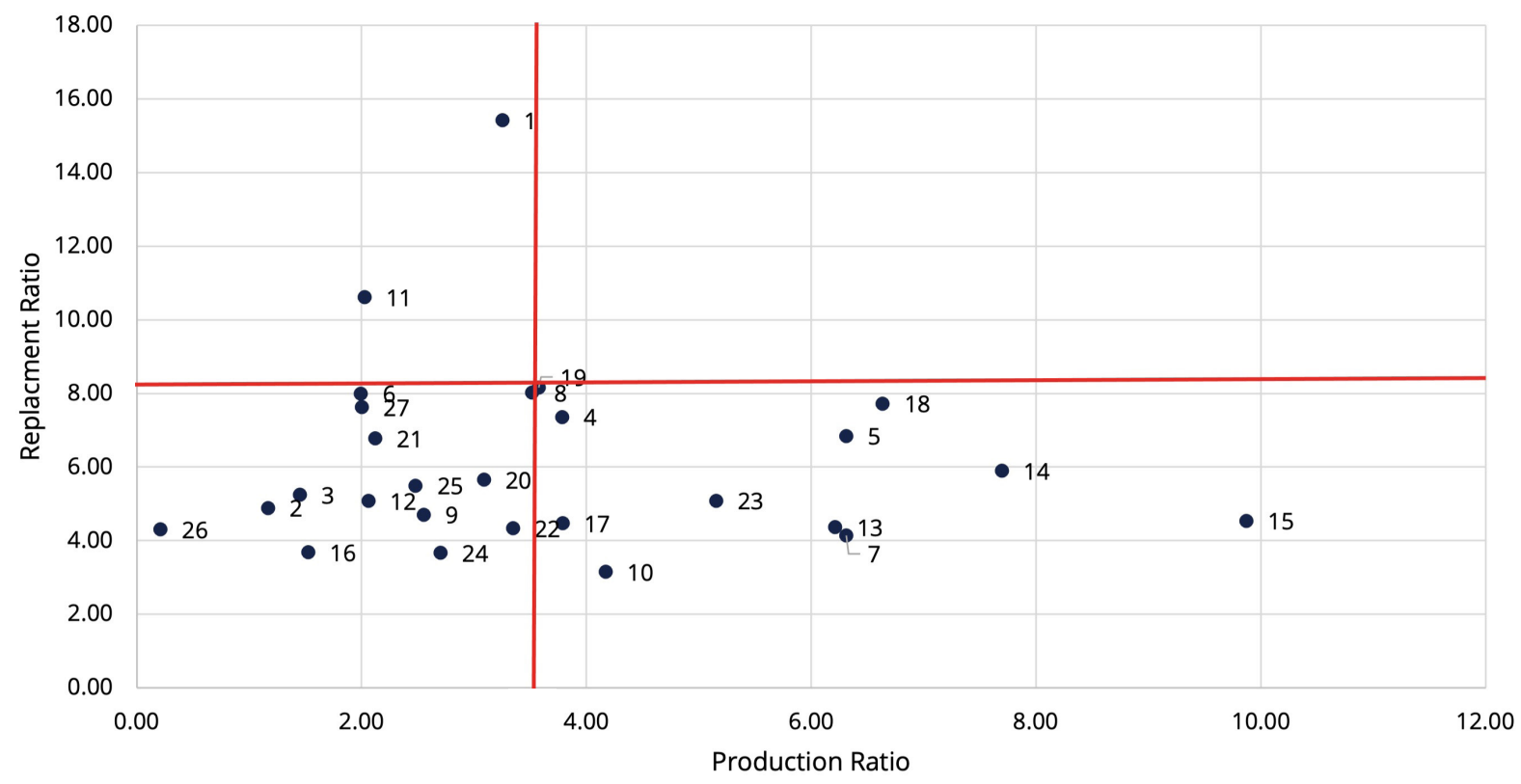


Figure 9b. Production Ratio in Relation to Replacement Ratio by Department, Year 2

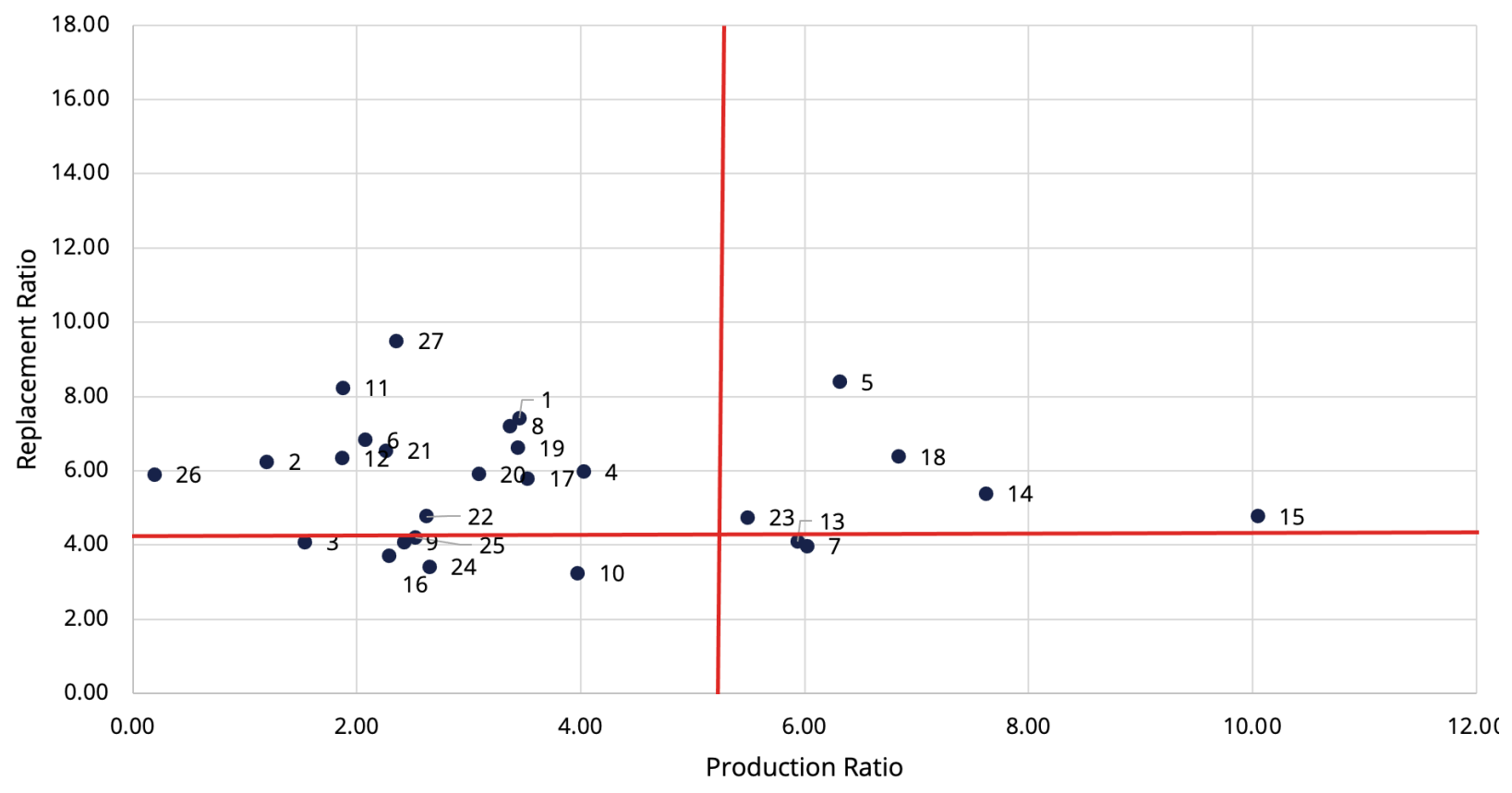

By observing the matrix diagram each year, it is possible to determine which departments or programs are strong and strengthening or which ones are weak and declining. Using the strategic measurement model discussed by Brown (1986) above, one can determine how a department or program's placement on the matrix adheres to the institution's success fundamentals as well as its long-term goals and objectives. Employing strategic planning, the administration may decide to maintain current support for the department or program, allocate resources to increase promotion and recruitment, consolidate the department or program within another department or program, or defund the program and use the saved revenue to enhance stronger programs.

One drawback from using the matrix is that the variation of the replacement and production means could be caused by a significant upward or downward shift of only a few departments (skewness), so program strengthening/weakening

may be masked by the fact that the mean from one year to the next shifted. To address this issue, the ratios should be evaluated on their own as well as in the relative context of the mean.

Because both the Viability Index and the Viability Matrix are easy to create, read, and understand, these tools can be shared with deans and department chairs for use in strategic planning, program reviews, and resource allocation.

\section{USING THE VIABILITY INDEX WITH DEPARTMENTAL BUDGETS}

Although the Viability Index by itself produces a lot of information about the strength of an academic program or department, an examination of expenditures is also important to understanding completely how well a program or department is doing. Clearly, some programs like science, 
engineering, and music cost significantly more to operate than do others like English, history, or sociology. Therefore, departments with the same Viability Index may be considerably different regarding its expenditures, and this factor should be taken into consideration when looking at the overall health of a department or program.

The focus of this article was to introduce the concept of the Viability Index in its purest form. Budget numbers were intentionally left out of the calculation of the index for the following reasons:

- The strength of the Viability Index should stand alone from the budget because it is concerned only with the recruitment of majors, replacement of graduates, and the production of credit hours. These are all key components to program or departmental viability.

- While the Viability Index is designed to be computed at multiple levels of the institution, adding a budget component to the index would be problematic, especially at the program level. Within the academic area, most budgets are distributed at the department level and are not readily divided or accounted for within the program level.

However, now that a single Viability Index can be created that considers majors, graduates, and credit hours, the index could be easily used as a divisor with the departmental budgets to create a cost per unit of viability (CPUV).

For example, say Department A has a Viability Index of 20.02 and a departmental budget of $\$ 1,102,054$. The budget divided by the index would be a $\$ 54,557$ CPUV. Department B has the same index of 20.2 but a budget of $\$ 524,142$. The CPUV for this department would be $\$ 25,948$, which is considerably less than
Department A. Therefore, the viability of budget numbers as compared to the Viability Index can give a dynamic and comprehensive overview of how a department is actually doing.

The institution will need to decide what expenditures are used. In most cases, nonpersonnel or academic support (equipment, supplies, software, etc.) could be parsed out of total expenditures to determine the CPUV.

\section{CONCLUSION}

As this article has demonstrated, ratio analysis can be a powerful tool in higher education. Ratios can be used as devices to analyze and interpret the health of an institution and to assist in determining the direction in which it should move. Ratio analysis can also help administrators evaluate whether the institution is doing better in a given year compared to the previous year; in addition, it can indicate if the institution is doing better or worse than other institutions within the same geographic location or with a similar role, scope, and mission.

Academic departmental or program viability is, in large part, a function of the ability of a department or program to attract and retain students as well as to generate vital revenue through credit hour production, to support the department as well as the institution. While the success of a department or program can also depend on factors outside the institution such as the economy, availability of high school students, and the marketability of the program, other components can be controlled by the department. Past methods of determining viability have typically used only one of these important components. The Viability Index, however, clearly measures the strength of a department in 
relation to the degree to which it is able to replace its graduates while also determining how many credit hours it generates in relation to the overall institution.

The Viability Index is the product of the replacement ratio and the production ratio. These two ratios are relatively easy for administrators or an institutional research office to obtain and analyze, and both the index and matrices are easily understood and can be used in strategic planning, program review, and resource allocation. 


\section{REFERENCES}

Brown, G. (2014, October 28). NCAA graduation rates: A quarter-century of tracking academic success. National Collegiate Athletic Association (NCAA). http://www.ncaa.org/about/resources/research/ncaagraduation-rates-quarter-century-tracking-academic-success.

Brown, M.G. (1986). Keeping score: Using the right metrics to drive world-class performance. AMACOM.

Cook, B., \& Pullaro, N. (2010, September). College graduation rates: Behind the numbers. Center for Policy Analysis, American Council on Education. Retrieved June 27, 2011, from http://www.acenet.edu/links/pdfs/ cpa/2010_09_30_collegegraduationrates.html.

Lederman, D. (2017, October 12). The new, improved IPEDS. Inside Higher Ed. https://www.insidehighered.com/ news/2017/10/12/new-federal-higher-ed-outcome-measures-count-part-time-adult-students.

Minter, J., Scott Hughes, K., Robinson, D.D., Turk, F.J., Buchanan, A. D., \& Prager, F.J. (1982). Using ratio analysis to evaluate financial performance. New Directions for Higher Education (38) 24-38.

National Conference of State Legislatures. (2015). Performance funding for higher education. National Conference of State Legislatures. http://www.ncsl.org.

Tahey, P., Salluzzo, R., Prager, F., Mezzina, L., \& Cowen, C. (2010). Strategic financial analysis for higher education: identifying measuring, and reporting financial risks (7th ed.). KPMG Sweden.

Tucker, S.A. (1961). Successful managerial control by ratio analysis. McGraw Hill.

US General Accounting Office (GAO). (1989). Student athletes: Most schools meet proposed academic performance reporting requirements. Washington, DC. 